\title{
BITÁCORA: GIRA DE ESTUDIO Y CORRELACIÓN GEOLÓGICA-ESTRATIGRÁFICA PANAMÁ-99
}

\author{
Elena Badilla, Percy Denyer, Lepolt Linkimer \& Héctor Zúñiga
}

Esta actividad se realizó como una salida de campo internacional entre el 17 y el 26 de mayo de 1999. Participaron en total 18 personas: diez estudiantes de Geología, siete profesores de la Escuela de Geología y un colega del CIMAR. Teresita Aguilar Álvarez (Paleontóloga, Directora de la Escuela), Percy Denyer (Coordinador de la Gira), los profesores de la Escuela Centroamericana de Geología: Guillermo Alvarado Induni, Walter Montero Pohly, Siegfried Kussmaul, Luis Obando Acuña y Guillermo Salazar Mondragón. Jorge Cortés Nuñez de la Escuela de Biología. Los estudiantes: Ivonne Arroyo Hidalgo, Elena Badilla Coto, Marta Cháves Quirós, Ignacio Cháves Salas, Paulo Hidalgo Odio, Leopold Linkimer Abarca, Raúl Mora Amador, Carlos Ramírez Umaña, Carolina Sigarán Loría y Héctor Zúñiga Mora.

La Universidad financió el vehículo, incluyendo el chofer. Además la Vicerrectoría de Investigación y el Rector ayudaron con \$1.500,00. Este monto fue utilizado para pagar los almuerzos, el combustible dentro de Panamá, el ascenso al volcán Barú en vehículos doble tracción contratados especialmente, transporte en taxi marítimo de Chiriquí Grande a la isla Colón en Bocas del Toro y el combustible de la lancha que nos suministró el Smithsonian para el trabajo en Bocas.

Desde un punto de vista académico, se cumplieron los siguientes objetivos:

a) Establecer correlaciones de índole geológico-estratigráfico de varias de las unidades geológicas. b) Establecer nuevos vínculos de cooperación y elaboración de proyectos.

c) Enseñanza y discusión de diferentes afloramientos.

d) Mantener el carácter Centroamericano de nuestra Escuela.

A continuación se detallará el itinerario de la gira, las localidades mencionadas corresponden con la numeración de la Figura 1.

14 de mayo: Previo a la gira se hizo un breve taller sobre la Geología de Panamá. Participaron los profesores Walter Montero, quien habló sobre la ubicación tectónica y evolución de Panamá; Guillermo Alvarado trató el volcanismo del Neógeno y Cuaternario; Jorge Cortés habló sobre el desarrollo de corales y biodiversidad de Bocas; y el geólogo Jorge Obando trató las secuencias sedimentarias de Panamá.

17 de mayo: Salimos en la mañana de la Escuela de Geología. En la tarde hicimos la primera parada en la falla Canoas, se discutieron las implicaciones geológicas de esta falla neotectónica. Posteriormente pasamos la frontera y llegamos a dormir a Boquete.

18 de mayo: Temprano en la mañana iniciamos el ascenso al volcán Barú (Loc. 1, Fig. 1), en vehículos doble tracción. Los vehículos tuvieron serios problemas para ascender y tuvimos que hacer el último tramo a pie. Sin embargo, pudimos recolectar muestras de las lavas andesíticas 
ricas en anfíbol y una espesa capa pliniana de pómez. Valga recordar que la última actividad de este coloso de más de tres mil metros de altura, fue hace unos 500 años. Dormimos en Boquete.

19 de mayo: Salimos con rumbo a la península de Soná. Visitamos varios afloramientos de rocas volcánicas. Cerca a Tolé observamos una colada de andesita con textura hialopilítica (Loc. 2). Corresponde con el Grupo Cañazas del Mioceno Superior (Anónimo, 1991). Cerca de la ciudad de Soná (Loc. 3) observamos basaltos con una composición mineralógica muy similar al Grupo Aguacate de Costa Rica. Se continuó el viaje hasta llegar a dormir a Chitré a las 9 p.m.

20 de mayo: Visitamos una localidad supuestamente fosilífera en las cercanías de Pesé (Loc. 4), que resultó ser un conjunto lodolitas del Grupo Maracas del Oligoceno (Anónimo, 1991), las cuales estaban deformadas e intruidas por diques. En la tarde trabajamos en un extenso acantilado en la playa Riomar (Loc. 5). Se hicieron columnas detalladas de parte del acantilado. Correspondiente a depósitos cuaternarios volcánicos y fluvio-volcánicos, relacionados con facies distales de la actividad del volcán El Valle. Estos depósitos corresponden con el Grupo Agua Dulce del Holoceno (Anónimo, 1991). Valga decir, que estos afloramientos son espectaculares, presentan estructuras como bioturbaciones, estructuras de carga, en almohadilla y en plato, fallas y pliegues sin-sedimentarios. Después continuamos el viaje hasta la ciudad de Panamá.

21 de mayo: Llegamos al Instituo Smithsoniano de Investigaciones Tropicales (STRI), donde nos recibieron de forma espléndida, y con na explicación detallada de los alcances de las investigaciones que realiza este Instituto, en un

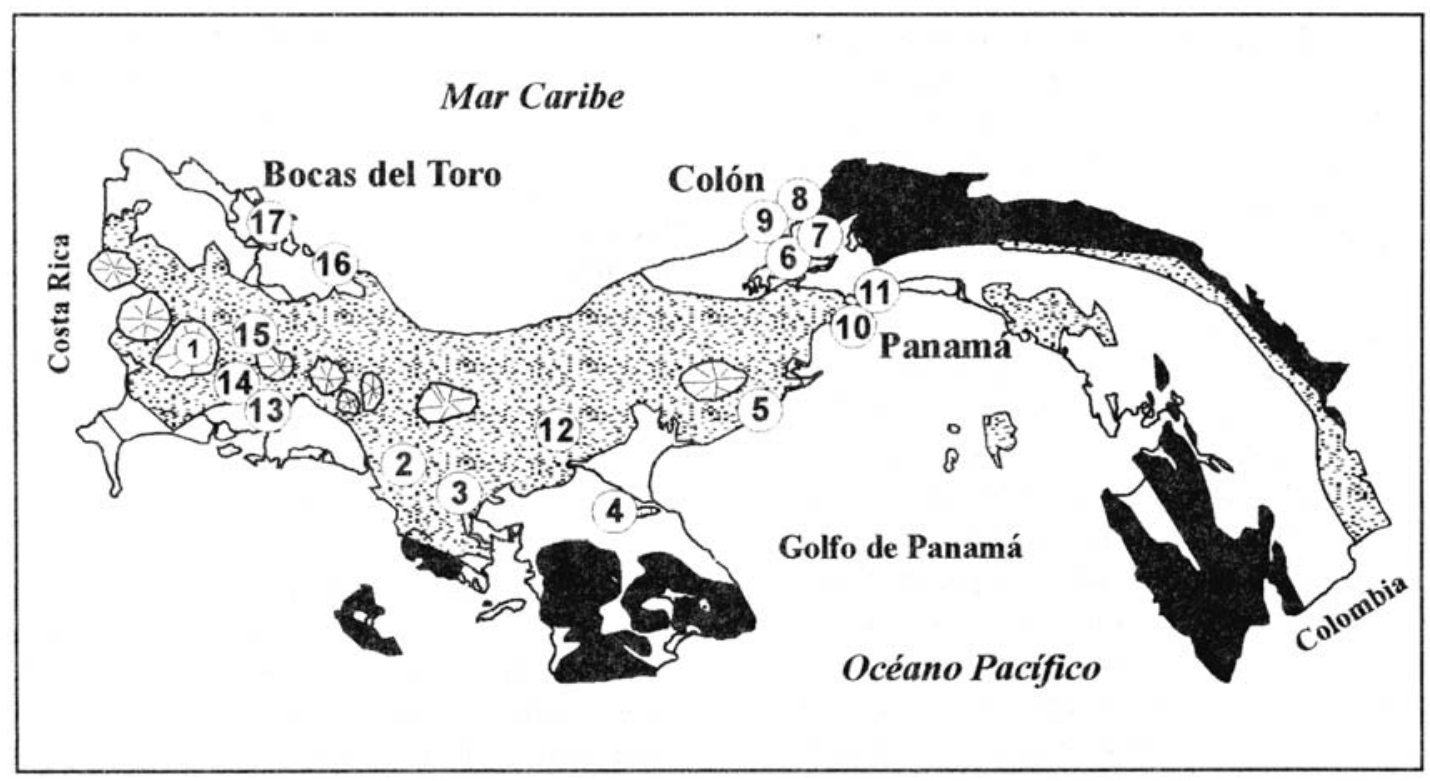

$100 \mathrm{~km}$

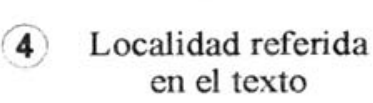

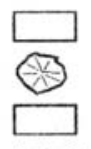

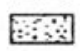

Pasen

\section{Rocas Sedimentarias del Cuaternario Rocas volcánicas del Cuaternario Rocas Sedimentarias del Terciario} Rocas ígneas indiferenciadas del Terciario Secuencia ofiolítica del Cretácico- Paleógeno?

Fig. 1: Mapa geológico generalizado de Panamá (basado en Anónimo, 1991). Se indican las localidades geológicas visitadas. 
país del tercer mundo, pero con las facilidades de un país desarrollado. Realmente es destacante el manejo de información de la Biblioteca. A medio día partimos hacia Colón, donde la Dra. Helena Fortunato nos mostró la Formación Gatún (Mioceno Superior), cerca a la población de Sabanita (Loc. 6). Frente a la refinería Panamá se observó un depósito de plataforma para-autóctono muy rico en fósiles (Loc. 7). En la población de Cativa (Loc. 8), vimos otro afloramiento de Gatún con abundantes dientes de tiburón, bancos de ostras y péctenes. Por último, en el fuerte San Lorenzo arenitas sin fósiles, masivas y muy bioturbadas de la Formación Chagres del Plioceno Superior (Loc. 9). Recolectamos muestras de fósiles para el Museo de la Escuela de Geología. Estuvimos de vuelta en ciudad de Panamá en la noche.

22 de mayo: Visitamos las rocas volcánicas que dan sustento al puente de Las Américas. En la isla Naos (Loc. 10), donde afloran andesitas con fracturas de disyunción columnar, también tuvimos oportunidad de observar los acuarios de investigación de corales del Smithsonian y la exposición normal al público. Posteriormente hicimos una visita a las exclusas de Miraflores.

23 de mayo: En el Casco Viejo de la ciudad de Panamá (Loc. 11), observamos las rocas sedimentarias de la Formación Boca del Mioceno Inferior-Medio, con una destacante bioturbación por Thalassinoides. Posteriormente, con destino a David, hicimos dos paradas, la primera en el río San Juan (Loc. 12) para observar unas ignimbritas, con una estructura columnar espectacular. Después una visita a la iglesia de San Francisco, la cual fue afectada, por el terremoto de 1822, al igual que el de Limón de 1991. Se llegó a dormir en David.

24 de mayo: De David a Chiriquí Grande hicimos el levantado de por lo menos 7 afloramientos que incluyen las rocas volcánicas (Formación Virigua del Mioceno Superior, Anónimo, 1991), que conforman la Sierra Occidental de Panamá. Entre estos destacan los depósitos volcaniclásticos de los kilómetros 26 y 43, así como las lavas andesíticas del río Brazo del Hornito (Loc. 13,14 y 15). La similitud de estas rocas, con la unidad geológica Aguacate, de Costa Rica, es sorprendente. El recorrido de Chiriquí Grande a la isla Colón (Bocas) se hizo en una lancha taxi.

25 de mayo: En una lancha contratada por el Dr. Anthony G. Coates, Director del Smithsonian Tropical Research Institute, visitamos la península Valiente y algunos islotes como Finger Island (Loc. 16) Una secuencia que empieza con depósitos turbidíticos, seguidos por una brecha volcánica de composición feno-andesítica intruida por diques fenodacíticos, y sobre esta secuencia afloran paleo-arrecifes. De acuerdo a Coates (com. esc., 1999) las turbiditas corresponden con sedimentos pre-istmicos y las brechas basálticas marcan el inicio del arco volcánico del Mioceno Medio tardío. En general, los afloramientos visitados corresponden con lo que Coates denomina Grupo Bocas del Toro; Anónimo (1999) los agrupa en la Formación Gatún (Mio-Plioceno), que en algunas localidades como Finger Island tiene una gran cantidad y diversidad de moluscos. En la tarde se hizo "snorkeling" en un arrecife actual en cayo de Agua (Loc. 17), como punto de comparación con los arrecifes fósiles. En la noche Guillermo Alvarado hizo un resumen de los principales aspectos de la gira y se concluyó con un discurso de la Directora de la Escuela, Teresita Aguilar, y el Presidente de la Asiciación de Estudiantes, Ignacio Cháves, para finalizar con una cena de despedida.

26 de mayo: Retorno a la Ciudad Universitaria Rodrigo Facio, vía Chiriquí Grande, David, San José.

\section{REFERENCIAS}

ANÓNIMO, 1991: Mapa Geológico de la República de Panamá.- Ministerio de Comercio en Industrias, Dirección General de Recursos Minerales, escala 1: 250000.

COATES, A.G. \& OBANDO, J., 1996: The Geologic evolution of the Central American isthmus.- En: Jackson, J.B.C., Budd, A.F. \& Coates, A.G. (Eds.). Evolution and environment in tropical America.- Chicago, The University of Chicago Press: 21-56. 